(2) Between the first day of June in any year and the date which is four clear weeks after the nomination meeting of the Council, written nominations, accompanied in each case by the nominees' written consent to stand for election, may be lodged with the Registrar, provided that each such nomination is supported in writing by not less than 12 Members of the College who are not members of the Council.

(3) An election by ballot shall be held in accordance with the provisions of the Regulations

The nominating meeting of the Council will be held on 28 April 2000 and the last date for receiving nominations under (2) above will therefore be 25 May 2000. Professor John Cox is in his first year of office as President and is therefore eligible for re-election.

\section{The Royal College of Psychiatrists Winter Business Meeting 2000}

The Winter Business Meeting of Council was held at the Royal College of Psychiatrists on 31 January 2000.

\section{Minutes}

The Minutes of the Winter Business Meeting held at the Royal College of Psychiatrists on 3 February 1999 were approved as a correct record.

\section{Election of Honorary Fellows}

The following were elected to the Honorary Fellowship:

The Right Honourable Sir Stephen Brown PC; Dr Robert Kendell, CBE; Professor Israel Kolvin; Professor Juan Lopez-Ibor Alino; Professor Toma Tomov.

\title{
reviews
}

\section{CAMDEX-R: The Cambridge Examination for Mental Disorders of the Elderly}

By Martin Roth, Felicia A. Huppert, C. Q. Mountjoy and Elizabeth Tym. Cambridge: Cambridge University Press. 1998. 180 pp. $£ 95.00$ (hb). ISBN 0-521-46261-4

This pack consists of a book including the questions in the Cambridge Examination for Mental Disorders of the Elderly; a computer disk onto which answers can be entered and from which questionnaires can be printed; and a smaller book with pictorial materials for cognitive examination. Within the main book there is a structured clinical interview; a brief neuropsychological battery; a structured interview with a relative; the diagnostic criteria from DSM-IV and ICD-10 for dementia and other categories including differential with depression. The CAMDEX-R also gives operational criteria which it suggests are used for clinical diagnosis and guidelines for classifying dementia according to clinical severity.

The first aim is to enable a differential diagnosis of dementia to be made according to the most recent criteria with the materials needed (apart from for physical examination and biochemical examination) included. The book gives the range of information required for differential diagnosis of the varying forms of dementia available in a single standardised interview and examination pack. However, I found it surprising that the criteria for Alzheimer's disease and vascular dementia are not given, although I agree they are fairly well known, but you could argue that about the rest of the material as well. Most mental health professionals know how to elicit the history or mental state.
The pack is designed so that different mental health professionals can use it. However, a physical examination and blood tests are needed to fill in the checklists. As a result only medically trained professionals can use the pack to make a differential diagnosis.

The computer pack has no installation instructions in the handbook. Once installed I was pleased to see that it was year 2000 compliant, but it would accept ridiculous dates for the year the interview was done, for example, 1957. The package is not as professionally laid out as the handbook and is DOS based. I was disappointed that the diagnosis had to be entered into the computer package by the interviewer, as I was hoping that the diagnostic criteria would be matched up with the answers to give an indication as to how they were fulfilled even if the programme did not come to a diagnosis. The GMS-AGECAT (a similar package designed by Professor Copeland and his team in Liverpool) comes to a standardised diagnosis from the information given with which the interviewers are free to disagree clinically. It would be helpful if CAMDEX-R did this as well. The authors state that they are currently developing a computer programme for examining individual scores obtained versus expected scores on both the total and the sub-scales based on demographic characteristics.

In summary, the CAMDEX-R is a wellorganised and generally comprehensive research instrument for the differential diagnosis of dementia. The materials are beautifully laid out and a pleasure to handle. It would be a helpful research tool in providing standardised assessments. The computer package is, however, disappointing.

Gill Livingston Senior Lecturer in Psychiatry, Department of Psychiatry \& Behavioural Science, University College London, Wolfson Building 48 Riding House Street, London W1N 8AA

\section{Differential Diagnosis in Psychiatry}

By S. Peters. Sheffield: Sheffield University Television. 1998.

£35.00 (1 video), $£ 180.00$ (all 7 videos)

The introduction included on each video stated that they provided "an overview of mental illness based on the ICD-10 classification". The diagnoses selected covered the main ' $F$ ' categories in the ICD-10 (organic disorders, psychoactive substance use, schizophrenic disorders, mood disorders, neurotic, stress-related and somataform disorders and personality disorders). The last video was called 'Challenging Cases'.

All but the last video consisted of the same format. First, text is displayed against a monochrome sagittal section of a brain with a voice over to introduce the clinical features of each diagnosis. This was followed by a brief clinical interview with the psychopathological features outlines at the beginning and captioned as the interview proceeded. Last, the differential diagnosis for the disorder was again outlined in text according to the ICD-10 diagnostic hierarchy. The seventh video 'Challenging Cases'presented four interviews of difficult presentations for group discussion.

The videos have been professionally produced, financed by pharmaceutical companies, and provide a clear introduction to the basis of differential diagnosis in psychiatry. In my opinion they are probably best suited to undergraduates rather than a postgraduate audience and should be shown separately. The patients included in the interviews seemed somewhat unreal, and I assumed that they were actors following a script. Also the credits indicated that the tapes were "written by Dr Steve Peters" whom I assumed had also 'acted' as the interviewer. 